\title{
Radar interferometry based settlement monitoring in tunnelling: Visualisation and accuracy analyses
}

\author{
Steffen Schindler ${ }^{1}$, Felix Hegemann², Christian Koch $^{3^{*}}$ D, Markus König ${ }^{2}$ and Peter Mark ${ }^{4}$
}

\begin{abstract}
Background: The accurate, efficient and economical monitoring of settlements caused by tunnel boring machines, especially in regions of particular interest such as critical inner city areas, has become an important aspect of the tunnelling operation. Besides conventional terrestrial based methods to capture settlements, satellite based techniques that can accurately determine displacements remotely, are increasingly being used to augment standard terrestrial measurements. However, not much attention has been paid to analyse the accuracy of satellite based measurement data. In addition, there is also a lack of studies on how to visualise the resulting huge amount of data in the context of both the tunnel advancement and the existing building infrastructure.
\end{abstract}

Methods: This paper introduces the basics of settlement monitoring using radar interferometry methods, in particular showing the results obtained by processing radar images from the TerraSAR-X satellite to monitor a downtown construction site in Düsseldorf, Germany, where a new underground line ("Wehrhahn-Linie") is being built. By comparing terrestrial measurements with remote satellite based settlement data in temporal and spatial corridors, the accuracy of the radar interferometry method is shown. Moreover, a $4 \mathrm{D}$ visualisation concept is presented that correlates satellite and terrestrial based settlement data correlated with above-ground buildings and boring machine performance parameters within a Virtual Reality (VR) environment.

Results: By comparing up to 23,000 pairs of satellite and terrestrial based settlement data points of a real tunnelling project an accuracy of about $\pm 1.5 \mathrm{~mm}$ in the measurement of deformation using the method of radar interferometry in urban areas can be stated. In addition, providing a visual analysis of data sources within a VR environment, the accuracy of terrestrial and satellite-based measurements can be visualised in different time steps. Sources of error that affect the degree of accuracy, such as atmospheric conditions, systematic errors in the evaluation of radar images and local events in the spatial corridor, can be quantified. In addition, the 4D visualisation can help reveal direct interdependencies between settlement data and boring machine performance data.

Conclusions: The Persistent Scatterer Interferometry (PSI) based on high resolution radar images of the TerraSAR-X satellite, in combination with conventional ground-based terrestrial measurements, provides a new settlement monitoring approach in tunnelling. For example, due to minimized surveying works and disruptions of construction activities on site and due to the large settlement area coming with a high magnitude of settlement data points, this combined monitoring approach is very practical and economical. Moreover, by visualizing the settlement data properly, the risk of damage of surface structures can be analysed and understood more precisely, which increases the safety of underground works.

Keywords: Settlement monitoring, Mechanised tunnelling, Settlement visualisation, Accuracy analysis

\footnotetext{
* Correspondence: christian.koch@nottingham.ac.uk

${ }^{3}$ Centre for Structural Engineering and Informatics, University of Nottingham,

University Park, Nottingham, NG7 2RD, United Kingdom

Full list of author information is available at the end of the article
}

\section{说) Springer}

(C) 2016 Schindler et al. Open Access This article is distributed under the terms of the Creative Commons Attribution 4.0 International License (http://creativecommons.org/licenses/by/4.0/), which permits unrestricted use, distribution, and reproduction in any medium, provided you give appropriate credit to the original author(s) and the source, provide a link to the Creative Commons license, and indicate if changes were made. 


\section{Background}

The increase in traffic in areas of high population density (conurbation) has resulted in the erection of new underground traffic facilities as a means to alleviate potential congestion problems (ITA Commitee on Underground Space (ITACUS): www.itacus.ita-aites.org 2010). However, during the construction of such facilities using TBMs, the risk of damage caused to buildings and other structures rises with the progressive reduction in tunnel covering. Therefore, the methods and techniques currently used in the tunnelling process must be substantially improved to counteract these possible negative effects. An important task in research and practice is therefore, on the one hand, to minimize the resulting settlements by improving machine technology and, on the other hand, to control the magnitude of the settlements and their consequences by an area-wide, exact monitoring. Of the latter point, several very precise terrestrial measurement methods representing the state-of-the-art are available, nevertheless, these procedures are time and material consuming. Additionally, to implement these procedures it is necessary to install and operate instruments on-site in or at buildings over a long time period (Kavvadas 2005; Van der Poel et al. 2005).

For some years now, technological progress in satellite based remote sensing using radar waves has made it possible to capture subtle displacements on the earth's surface with millimetre accuracy (Bamler et al. 2008; Arangio et al. 2012; Giannico \& Ferretti 2012; Herrmann 2009). Thus, using this technology, expensive and labour-intensive on-site installations are not necessary. Within the framework of the collaborative research centre SFB 837 "Interaction modelling in mechanized tunnelling," financially supported by the German Research Foundation (DFG), the aim is to implement and to scientifically evaluate an independent settlement-monitoring process at the construction site of the underground railway "Wehrhahn-Linie" in Düsseldorf. For this purpose, the Institute of Concrete Structures at the RuhrUniversität Bochum as Principal Investigator (PI) cooperates with the German Aerospace Centre (DLR), the state capital city of Düsseldorf and the TU Braunschweig (Mark et al. 2012).

The main research questions in this project are:

a.) How precise is the relatively new radar interferometric method compared to traditional terrestrial measurements in the field of mechanized tunnelling?

b.) How can terrestrial and radar interferometric settlement data be best visualised for further analyses?
The focus is mainly on the question of accuracy, verified by several thousand comparative calculations with terrestrial measurements. In order to analyse possible resulting deviations from comparative calculations, a visualisation method will be used.

This article presents the results of an accuracy analysis and methods that have been developed to analyse and visualise settlement data in a virtual reality (VR) environment. In particular, the next sections summarize the important basics of terrestrial and satellite based settlement-monitoring.

\section{Current practice of settlement monitoring in tunnelling}

The construction of tunnels induces unavoidable settlements on the earth's surface. The settlements arise from volume loss and stress changes in the ground, for example during shield driving, and they can damage adjacent buildings (Burland et al. 2001; Giardina 2013). Especially in densely built urban areas, an area-wide and chronologically complete monitoring of settlements is a necessity to realise a tunnel construction project at an appropriate safety level. The greenfield settlement trough due to tunnelling induced volume losses can be described by semi-empirical equations (Gauß function), for example according to Peck (1969). If the building stiffness is taken into account, a precise description of the greenfield settlement trough gets more complex. The interaction between the building stiffness and the ground homogenises and reduces absolute settlements related to the position of the building in the settlement trough (Giardina et al. 2012).

Today, the state-of-the-art in settlement or deformation monitoring relies on classical terrestrial measurement methods and devices, for example water level gauges, levelling or measurements with tachymeters (Kavvadas 2005). The high accuracy and very short measuring intervals of terrestrial methods still make them unsurpassed. For example, the accuracy of measurements using water level gauges can be as high as $0.01 \mathrm{~mm}$, depending on the length of the measured section and the technique used (Witte \& Schmidt 2000; Jakobs et al. 2001). Data measurements are recorded manually or automatically, according to the requirements. The combination of permanently installed prisms and fully automatic tachymeters permits high accuracy and real time monitoring in intervals of less than an hour.

Despite the high levels of automation, there is still a significant amount of effort (in terms of personnel and materials) required on-site. Interruptions of the construction process on site and disturbances to residents due to survey services are also unavoidable. 


\section{Radar interferometry based monitoring}

Basics of the radar interferometric method (SAR)

Since the launch of the German radar satellite TerraSAR$\mathrm{X}$, optical remote sensing has become viable for settlement monitoring in tunnelling due to the increased geometrical resolution of the installed radar systems (Gernhardt et al. 2009). The radar waves from the active radar sensor are sent to the earth's surface and the radar echo (complex raw data signal) is received by the antenna of the satellite (Fig. 1). Depending upon the time delay and the strength of the received signal, Synthetic Aperture Radar (SAR) images can be derived. Furthermore, some additional physical properties, including the wave length, the angle of incidence, satellite state vectors and the time of data acquisition are known and recorded in the SAR image specification file. By comparing two different SAR images of the same location on the earth's surface, an interferogram - considering the phase-shift between the images - is derived. The side-looking radar sensor is independent of weather and lighting conditions. In the case of settlement monitoring, it is required to convert the displacement in the Line of Sight (LOS) into a vertical displacement component by neglecting the horizontal movement. Due to very small horizontal displacements, the error arising from this adjustment is often small.

The basic principle of radar interferometry is based on the comparison of two phases at the same position or the same object on the earth's surface (resolution cell). To identify displacements, therefore, the main task is to calculate the phase-shift or interferometric phase $\phi$. In doing so, the resolution of radar images is sufficient in the range direction, but lower in the azimuth direction due to the physical length of the antenna. To achieve a high geometric resolution, a special recording and analysis method will be used, the so-called Synthetic Aperture Radar technique
(SAR) (Klausing \& Holpp 2000). The length of the antenna will be artificially enlarged by using a specific combination of a number of pictures from successive satellite locations.

On closer examination, the interferometric phase $\phi$ consists of the components (Gamma Remote Sensing: Interferometric SAR 2007)

$$
\phi=\phi_{\text {flat }_{\text {Earth }}}+\phi_{\text {topo }}+\phi_{\text {disp }}+\phi_{\text {path }}+\phi_{\text {noise }}+n 2 \pi
$$

where $\phi_{\text {flat_earth }}$ describes the phase-component caused by earth curvature; $\phi_{\text {topo }}$ represents the phasecomponent which complies with the used surface model (height $z$; using a precise external digital surface model created by a laser-scan, for example, the influence to the accuracy is negligible small (Walter 2011)); $\phi_{\text {disp }}$ is the desired target value and represents the displacements on earth surface in the line of sight (LOS); $\phi_{\text {path }}$ expresses the time delay of the radar signal influenced by current atmospheric conditions (Hanssen 2001; Tarayre \& Massonnet 1996) and $\phi_{\text {noise }}$ is a component caused by unavoidable noise, for example a significant change in the reflection behaviour of a resolution cell (de-correlation). The two last phase-components frequently result in an incorrect determination of deformations. Components with wave lengths over $2 \pi$ are taken into account by the so-called "phase-unwrapping" term $n 2 \pi$. This is decisive for short-wavelength radar systems, such as the TerraSAR-X, with simultaneously high degrees of $\phi_{i}$.

Today, measuring and evaluation methods are preferred using 20 to 50 radar images. Employing various procedures, including external weather records, atmospheric disturbances can be eliminated broadly in order to generate a complete time series of settlements (Hanssen 2001; Tarayre \& Massonnet 1996; Schäfer 2012). Furthermore,

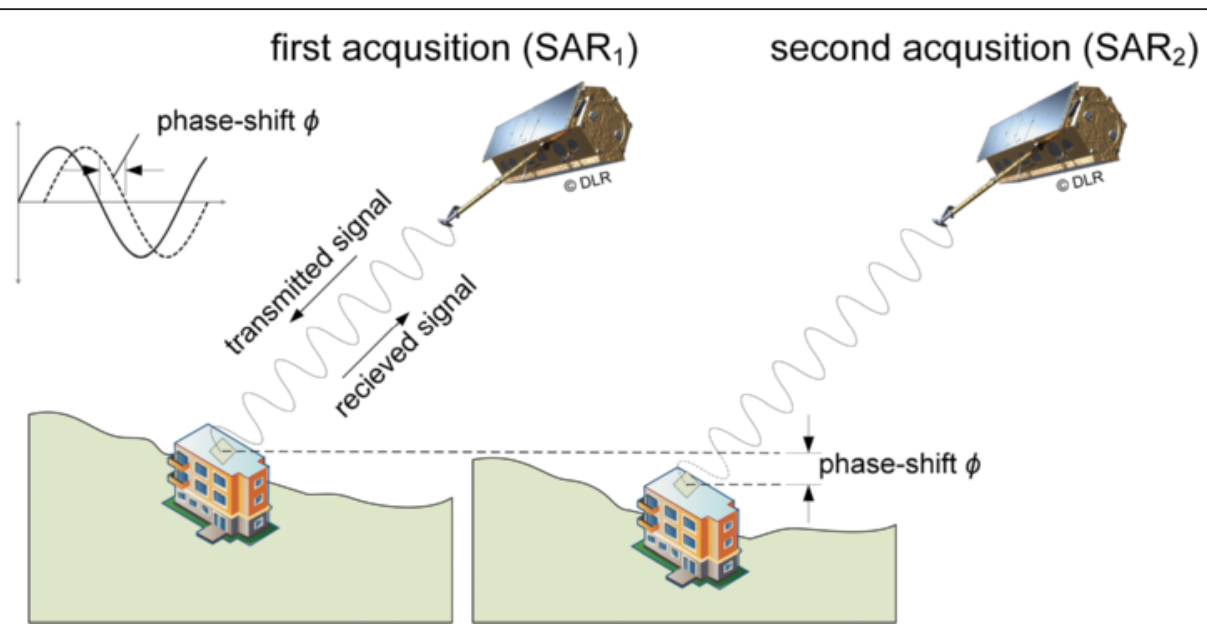

Fig. 1 Principle of Interferometric SAR in displacement monitoring. The illustrated displacement is derived from the phase-shift of two or more acquisitions 
during the observation period stable reflection properties (coherence) are required. Because these requirements are often not completely satisfied for the entire region of interest, Ferretti et al. (Ferretti et al. 2011; Ferretti, Prati et al. 2011) 2001 have, for the first time, based the interferometric analysis solely on independent and locally limited so-called "persistent scatterers" (PS). These local elements on the surface of monitored objects show such suitable backscatter properties that are also stable over time. This method is also known as Permanent Scatterer Interferometry (PSInSAR ${ }^{\mathrm{m} m}$ ).

Due to changes on the earth's surface, such as vegetation growth or moving objects (vehicles), backscatter properties can be strongly degraded and thus reduce or even eliminate desired coherences, making an interferometric analysis difficult or even impossible. The data recorded by the sensor data is represented in the SLC ("Single Look Complex") record as a "pixel image." For these "pixels," a time series can be derived from phase positions, that is, the deformation behaviour of individual pixels can be tracked very accurately over time.

Luckily, it turns out that the PS density is often high in urban areas, in contrast to open spaces with fields, meadows, fallow land or forest areas. The PS can often be mapped to relative small structural elements, including ledges, window niches or façade elements. A geo-referencing of individual PS in, for example, the Gauss-Krüger coordinate system often remains flawed, depending on the local knowledge of the topology (elevation model). Due to the oblique nature of the photographs or shade given by vegetation, no information is available in the so-called radar shadow. However, by combining additional radar recordings from other orbital positions, these negative effects can be considerably reduced.

A recent development of the Persistent Scatterer Interferometry $\left(\right.$ PSInSAR $\left.^{\mathrm{mm}}\right)$ marks the Distributed Scatterer Interferometry (Ferretti et al. 2011). In the so-called SqueeSAR ${ }^{\mathrm{mi}}$ method, the backscattered radar signals of several similar "pixels" are summarized and so, despite weak backscattering properties, de-correlation is reduced to a minimum.

\section{The monitoring project at the Wehrhahn-Linie}

For the radar interferometric settlement monitoring at the Wehrhahn-Linie construction site, 24 records of TerraSAR-X radar pictures were available for scientific use (Schindler 2014). These images were in the form of raw data in the period from January 2011 to December 2011 in the "Descending Mode," Orbit 63, Characteristic Strip Mode and recorded with $\mathrm{HH}$ polarization. They achieved a ground resolution of up to $3 \times 3 \mathrm{~m}$.

Image processing results in a list of active Persistent Scatterers, that is, particularly intensive reflective pixels. In the sphere of influence for the TBM in the so-called
"Ostast" (Eastern Branch), about 16,000 such PS could be detected. This corresponds to a PS density of about $26,000 \mathrm{PS} / \mathrm{km}^{2}$. For each PS, a time series is generated and the vertical displacement component is derived. Also, the SqueeSAR ${ }^{\mathrm{m} w}$ method can identify further Distributed Scatterer (DS) points. Disruptions, such as an unfavourable atmospheric conditions creates unwanted, but unavoidable gaps in the time series. Even temporary disturbances of the TerraSAR-X satellite itself or temporal and spatial conflicts with other users lead to gaps in the data stacks. Generally, an increase in the size of a data gap increases the risk of a possible decorrelation. For the present example, this implies that at the 24 recorded scenes in Düsseldorf the time interval between two data points in the time series does not necessarily correspond in all the cases to the 11 day satellite repetition rate, so de-correlation effects due to data gaps have arisen. In the following, if not explicitly stated otherwise, the term "PS" always includes "DS."

\section{Visualisation methods}

Tunnelling operations generate a huge amount of data, usually in the form of tables or documents. Data sources include details from the tunnelling design, the accompanying geological investigations and data from measuring devices. The diversity of tunnelling project data is often very large, resulting in complex data structures which can be confusing if particular portions have to be analysed within a specific context. Additionally, measurement data is often time dependent. During the investigation of time dependent data it is hard to conclude why a particular dataset has been captured at a particular point in time, and to determine which influences have an impact on the data values. Consequently, data stored in separate and diverse tables and documents obviously miss the dependencies to other aspects that might reveal relevant correlations. For example, let us assume that settlement data has to be interpreted. Measured settlement data can be represented in a table or diagram that shows the time dependent behaviour of individual settlement points. However, the relation of the point's location to its environment (at a building, on a walkway or on a street, for example) is unclear by solely considering its coordinates. Additionally, no conclusion can be made on how this point fits into its neighbouring settlement measurements in terms of noise. Furthermore, the cause of single settlements is usually unknown and the following question may arise: Is the settlement directly caused by the TBM which was advancing beneath the particular point or is the settlement due to something else? To answer these types of questions and to be able to better comprehend the extensive amount of tunnelling settlement data, a holistic, 3-dimensional visualisation of the tunnelling project is required. 
Visualisation also provides a certain degree of interactivity with the available data (Spence 2001). The data can be viewed from different perspectives using rotation and shift functions. Additionally, important situations can be viewed in a closer look using the zoom functionality. However, during construction projects measured data are often time dependent, such as the measured settlements. Hence, a graphical representation must be provided to visualise time dependent data. This can be achieved by creating animations. Animations can visualise time dependent data by defining a period of time which is run through a series of time steps. Animations also offer a great potential of human-computer-interaction to visually analyse dependencies. For example, the animation can be stopped to investigate an unexpected measured event at a specific point in time and then be continued.

This section presents a novel approach for the visualization of settlement monitoring data in tunnelling projects. This approach is divided into the following parts:

- Visualisation concept for correlating aspects using an integrated tunnel product model

- Visualisation concepts for discrete settlement data using point-oriented and area-oriented methods

- Animation concept for time-dependent settlement data correlated with operational machine data

- Software prototype implementation using a standard data format and a virtual reality environment platform

\section{Visualisation of correlating aspects in tunnelling}

A well-defined visualisation helps to structure and interpret generated information (Spence 2001). For example, different aspects of the tunnelling process, such as the ground (soil layers), the tunnel alignment, the advancement of the tunnel boring machine, and the building structures, needs to captured in one holistic view of the entire project. Accordingly, a Tunnel Information Model has been developed and is depicted in Fig. 2. Thus, dependencies between the different aspects, which may be hidden just by looking at tables, diagrams and documents, can easily be identified. For example, by visualizing the track of the tunnel alignment together with the building structures on the surface, it can be discovered which property lot is crossed underground by the shield machine.

By means of visualisation, correlations can be identified between these aspects and the resulting settlements on the surface. For example, the settlements might increase when the TBM has to advance through a soil layer boundary. Also, the correlation between measured data and process data can be identified. For example, the correlation

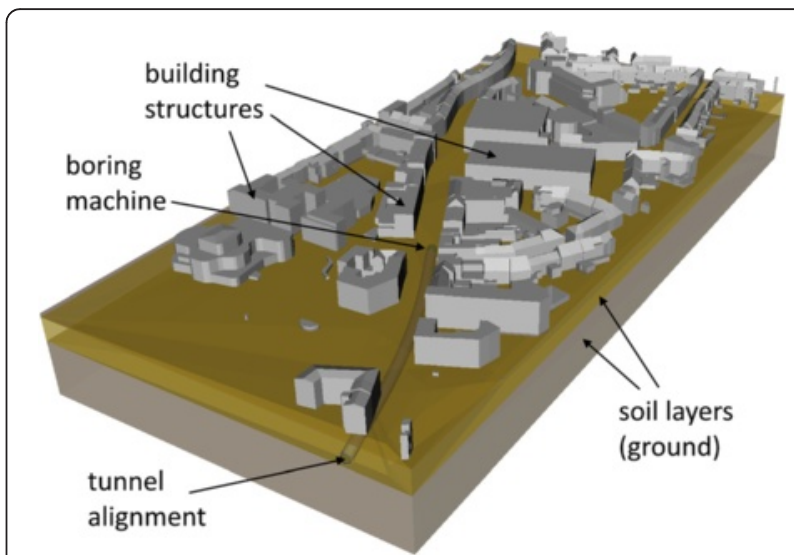

Fig. 2 Tunnel information model with sub-models for soil (ground), tunnel alignment (lining), boring machine and building structures, exemplified by the Wehrhahn-Linie project in Dusseldorf

between measured settlements and the position of the TBM at a specific point of time can be revealed by means of visualisation. The grouting pressure during the tunnel construction can also have an impact on the settlements. Using a proper visualisation, it can be reviewed how specific machine parameters, such as the face support pressure, may influence the magnitude of settlements and how settlements behave with respect to the pre-loading of the ground due to buildings on the surface. Thus, measured data has to be investigated with respect to these main aspects in order to identify and evaluate the correlation between them resulting in consolidated findings for decision making.

\section{Visualisation of settlements}

One crucial part of this paper is the visualisation of settlements. Settlements are time dependent data, which are usually measured in irregular time periods. This complicates the visualisation of the settlements, because there is probably not a single settlement value for each settlement point for each day of the tunnelling project. On the one hand, for example, the settlements based on the PSI measurements are determined in a constant time interval of eleven days. Thus, the authors propose to visualise the last known value of settlements up to the point of time that is considered. On the other hand, terrestrial settlements are usually measured manually in millimetres per day. Of course automated systems like a hose pipe level with a connected data logger might measure data in shorter time periods. However, daily measured data could lead to problems during the visualisation in terms of time scale. For example, if a settlement-sensitive event occurred at a certain point in time within one day, the consequences might not be seen if the settlements were measured at an earlier point in time of that day. Thus, settlement data should always been measured in adequately short time periods with 


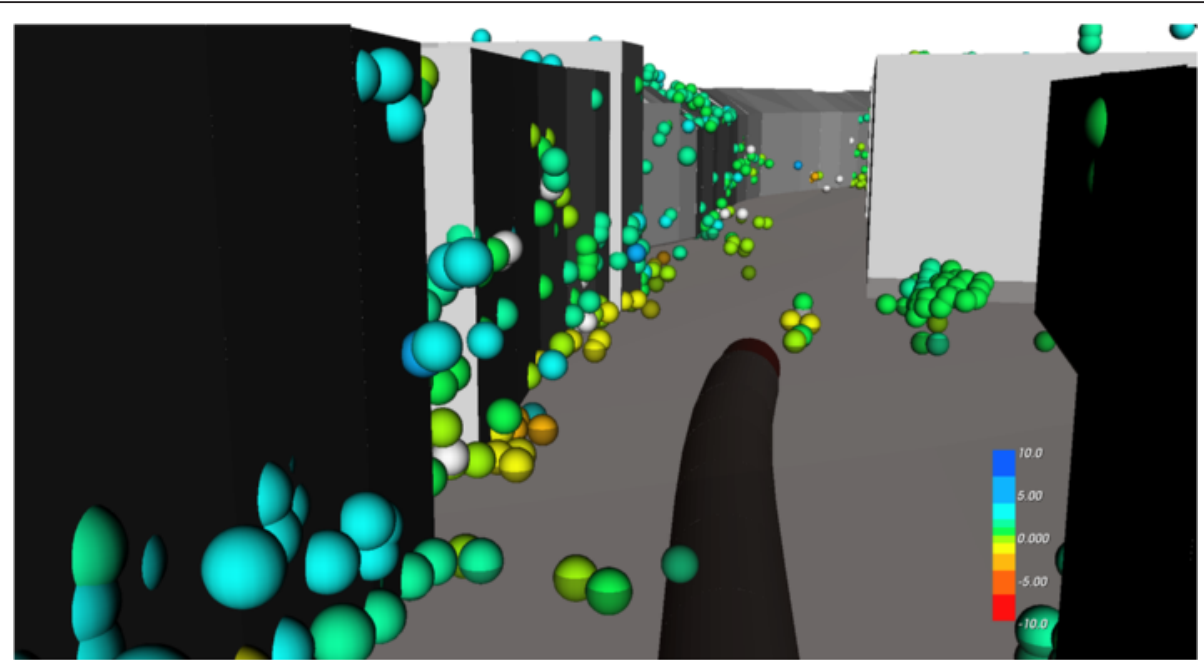

Fig. 3 Point-oriented and color-coded settlement visualisation of PSI data exemplified by the Wehrhahn-Linie project

regard to the risk of potential events that are highly sensitive towards settlements.

In order to visualise the magnitude of settlements individual values are represented using a colour gradient. The scale of the colour gradient should be defined for each project individually, because the range of values differs from project to project. For example, in the Wehrhahn-Linie project, a very tight scale of colours near the zero level (one colour value per millimetre) has been chosen. This scale range might increase in case of larger settlement values. However, settlement data are available as point data where each point is assigned with a number of key-value pairs containing the time stamp and the corresponding measured settlement value. These points can be visualised by different graphical representations.
One possibility is the representation by means of a single geometrical shape, like a sphere. In this case, the representation is point-oriented as it shows a certain measurement at a specific point. Additionally, the settlement value can be represented in other ways. First, a colour value corresponds with a single scalar settlement value. Second, the size of the geometrical shape (for example, the radius of the sphere) reflects the magnitude of the value. Third, the vertical position of the geometrical shape reflects the settlement's displacement. Figure 3 illustrates the point-oriented and color-coded settlement visualisation of the PSI data using the Wehrhahn-Linie project information. Please note that the persistent scatterer points appear at building foundations, at building roofs as well as at the road surface.

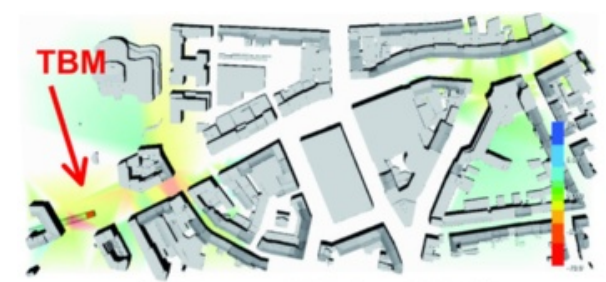

a) June 30th, 2011

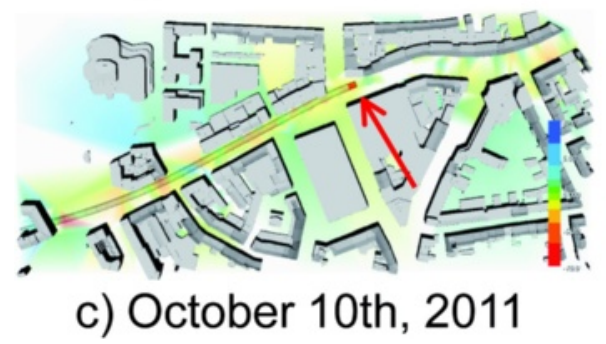

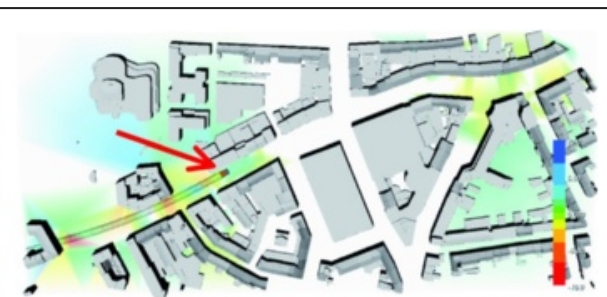

b) August 20th, 2011

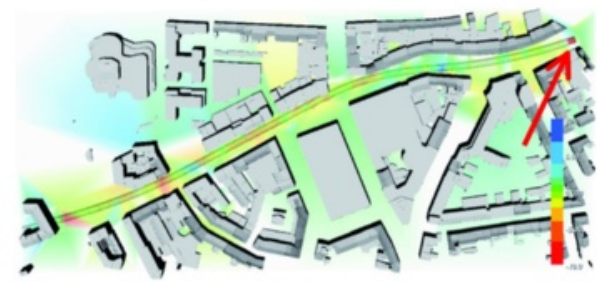

d) November 30th, 2011

Fig. 4 Animated terrestrial settlement visualisation using the triangulation method in several time steps June 30th (a), August 20th (b), October 10th (c) and November 30th 2011 (d) with corresponding position Tunnel Boring Machine (TBM) (red arrow), (Schindler et al. 2014) 
Another possibility to represent settlement data is by creating a triangulated mesh of the settlement points. This type of representation is area-oriented, as it provides an aerial overview of the situation (see Fig. 4). This method reflects the gradient of the settlement by the colour gradient. Thus, a settlement value for an arbitrary point within the settlement trough that has not been directly measured (the corner of a house, for example) can be anticipated more easily. However, this kind of representation should be evaluated critically, because the colour gradient is only interpolated on a logarithmic basis and adds synthetic information that has not been directly captured. Consequently, the further the distance to a measurement point, the more uncertainty must be considered.

Having discussed the two different ways of visualising settlement data, it can be concluded that a combination of both settlement representation methods might provide an optimal solution. For example, in a 3D environment the point-oriented method gives a much better illustration (compare Fig. 3), whereas in a $2 \mathrm{D}$ environment, such as a map, the area-oriented method is much more appropriate as it provides an aerial overview (compare Fig. 3, Fig. 4 and Fig. 5).

\section{Animation of advance driven settlements}

As mentioned before, animations provide a great potential of human-computer-interaction, in particular for time dependent data. They can visualise the development of certain time dependent aspects, such as advance driven settlements over time. In case of an unexpected and settlement-sensitive event, the animation can be stopped and the current situation can be investigated. In addition, the correlation between the position of the TBM and the surrounding settlements can be seen for each time step. Figure 4 depicts an animation of settlements consisting of four time steps (June 30, August 20,

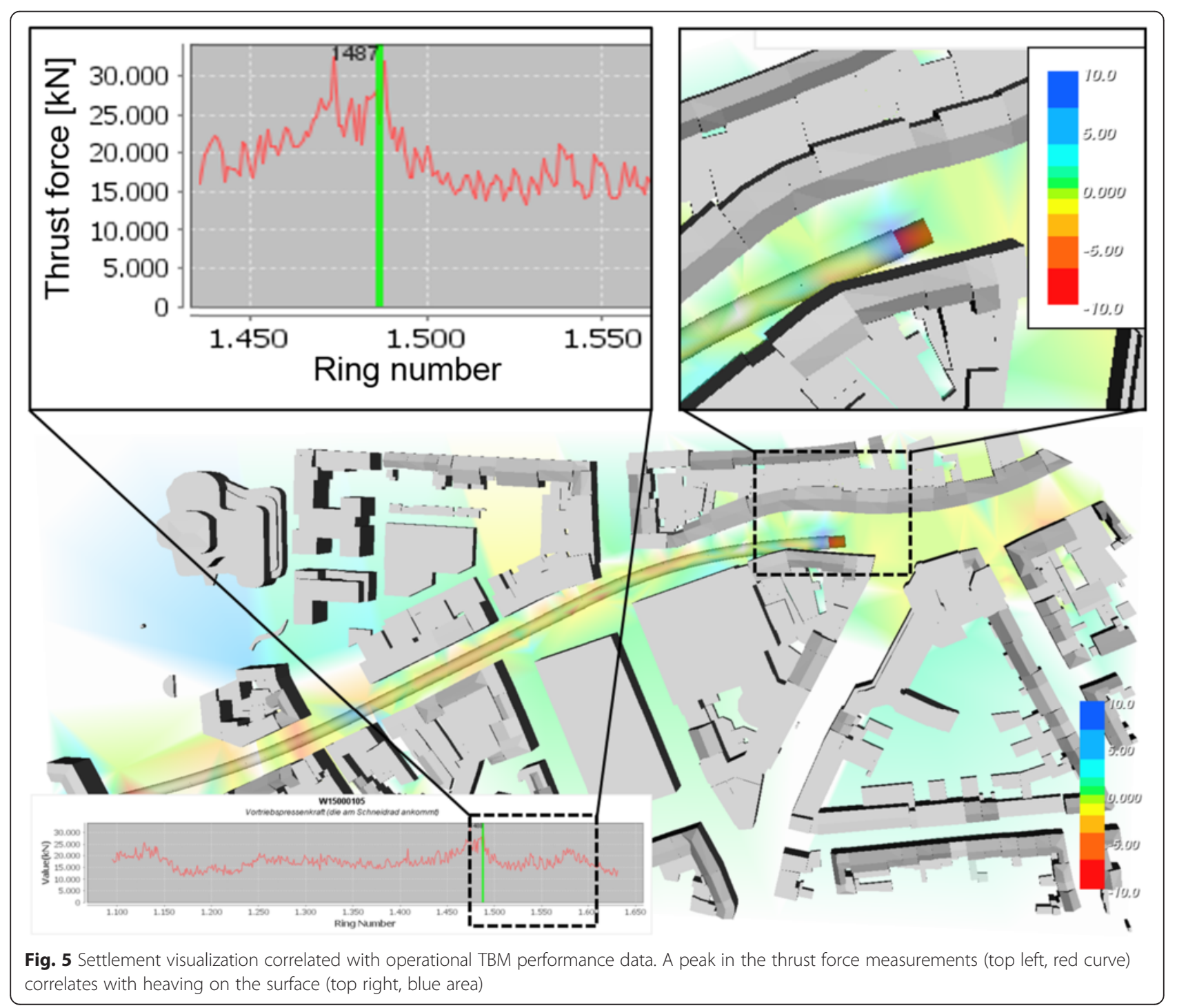


October 10, and November 30, 2011). The change of settlements due to the advancement process of the tunnel boring machine is clearly visualised.

Besides the position of the TBM, its operational performance data can be visualised over time together with the time dependent settlement values. For example, in case a settlement value is unexpectedly high, the corresponding thrust force value can be checked in order to determine if something went wrong. Figure 5 illustrates a specific project situation, in which the high thrust force value (Fig. 5, top left, peak in curve) is correlated with a heaving above the TBM (Fig. 5, top right, blue area). According to internal project information, the TBM had to drive through a bearing slurry wall that caused heaving on the surface.

\section{Visualisation implementation}

The visualisation implemented for this project consists of two major parts, namely the integrated tunnel product model and the virtual reality environment. The tunnel product model contains information about the ground, the tunnel, the TBM, the building structures and the settlement monitoring data (Schindler et al. 2014). This product model is based on the Industry Foundation Classes (IFC) (BuildingSMART 2013) notation, which is a standardized data exchange format for construction projects with respect to the Building Information Modelling (BIM) concept (Kymmell 2008). IFC captures geometric representations as well as semantic information of objects. Based on geometry information, a $3 \mathrm{D}$ visualisation of the entire product model is provided. The IFC-based viewer software has been installed on the Samsung SUR40 multi touch table (see Fig. 6). On the one hand, the IFC viewer software visualises diferent physical objects of the product model in terms of geometry (soil layers, building structures, tunnel lining, TBM), and, on the other hand, it provides and links the corresponding semantic information (soil layer properties, tunnel specifications, TBM characteristics) to each object. During a tunnelling project, several project members can work together and meet in order to discuss the project status. In such a situation, a table display might be too small to allow everyone in a room to follow the discussion. Therefore, a connection has been created to another computer in the network visualizing the project data in a virtual reality (VR) environment (Sherman \& Craig 2002). Within the VR context, shutter glasses are used to provide an immersive 3D view of the graphical objects on the VR wall (see Fig. 6). This provides an even better impression and comprehension of how single project data items interact and correlate with one another. The VR visualisation can be steered by touch on the table using the IFC viewer software. It also enables the user

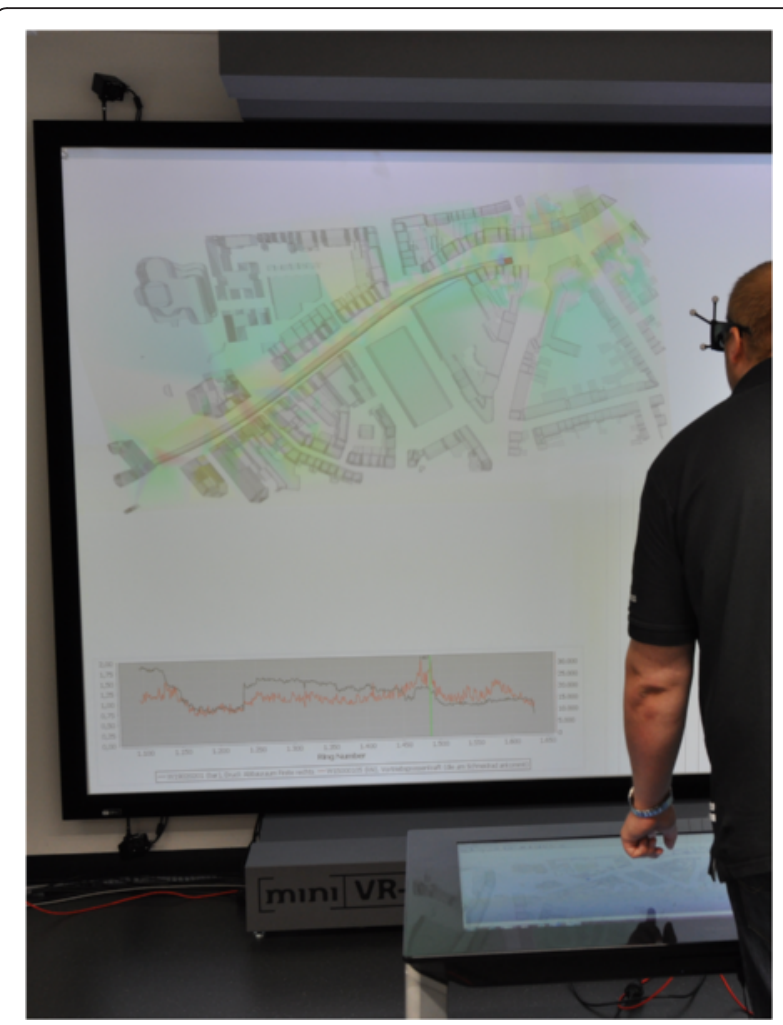

Fig. 6 Hardware setup for the settlement visualisation implementation using a touch-table and a 3D Virtual Reality (VR) wall

to create and steer animations while displaying them in the VR environment (Fig. 6).

\section{Accuracy analysis methods}

It is essential to properly verify and validate settlement measures, both to increase the acceptance and establishment of new measuring and monitoring methods as well as to provide indications to substantiate further investigations, including failure analysis of the above ground buildings. To this end, a comparison of settlement measurements using existing terrestrial measurement methods is suitable (Schindler 2014). Some individual studies have been carried out to estimate the accuracy of the Persistent Scatterer Interferometry (PSI) method, based on individual comparisons with terrestrial measurements over long time periods and large geographic areas ((Giannico \& Ferretti 2012; Hanssen et al. 2007; Walter et al. 2009). In (Hanssen et al. 2007), the relative differences of spatially distant settlements in various projects in the Netherlands have been compared using terrestrial methods and the PSI method. The standard deviations of the settlements at the N/S line in Amsterdam (Netherlands), for example, were determined to be between $1.7 \mathrm{~mm} /$ year and $3.0 \mathrm{~mm} /$ year. Settlements from the shield tunnelling were not considered. 
In this paper, satellite-based measurements (PS) are compared to classical geodetic measurements (TER) to investigate the precision of the true variance $\Delta_{\mathrm{PS}, \mathrm{ij}}$. TER includes not only tube level measurements at the foundations of buildings, but also classic levelling in the greenfield. The various terrestrial measurements $\tilde{X}_{T E R, j}$ (Niemeier 2008) are considered to be true values since the possible deviations of classical measurements are either negligible or completely known. However, it should be noted that the $n$ locations of PS and the $m$ locations of TER differ in area and height. Thus, couples of comparable values are assumed to lie at the "same position", if their distance remains within certain corridors in the ground. Now the same applies to time and time corridors. According to equation (1), the deviations $\Delta_{\mathrm{PS}, i j}$ (with $i=1$ to $n ; j=1$ to $m$ ) are computed as a component subtraction between the satellite-based measurements $m_{P S, \mathrm{i}}$ and the corresponding adjacent "exact" temporal and spatial terrestrial measurement $\tilde{X}_{T E R, j}$. Since the true value $\tilde{X}_{T E R, j}$ is a scalar quantity, it must be multiplied by the all-ones vector $\vec{e}$. Unlike in (Hanssen 2001), the settlement measuring points can be directly compared. The index $j=1$ to $m$ (maximum number of TER) is related to TER values.

$$
\begin{aligned}
\vec{P}_{P S, j} & =\left[\begin{array}{c}
\Delta_{P S, 1 j} \\
\Delta_{P S, 2 j} \\
\cdots \\
\Delta_{P S, n} j
\end{array}\right]=\overrightarrow{m_{P S}}-\vec{e} \tilde{X}_{T E R, j} \\
& =\left[\begin{array}{c}
m_{P S, 1}-\tilde{X}_{T E R, j} \\
m_{P S, 2}-\tilde{X}_{T E R, j} \\
\cdots \\
m_{P S, n}-\tilde{X}_{T E R, j}
\end{array}\right]
\end{aligned}
$$

The deviations $\Delta_{\mathrm{PS}, i j}$ are calculated conceptually with spatial and temporal corridors. To this end, adjacent TER and PS are identified throughout the area of interest. Due to different types of effects that are considered in more detail later, this concept leads to relative conservative values. In all methods, the relative change of height is always related to a so-called reference measurement of the corresponding series. Since the reference measurements of the terrestrial values can vary greatly over time compared to the satellite measurements, the reference measurements of the terrestrial values must therefore be transformed to the reference measurements of the PSI method. The transformation has to be done very carefully, otherwise the accuracy of the analysis will be decreased by an additional error component $\Delta^{*}$. With the chosen tiered approach to transformation of heterogeneous terrestrial measurements, the error component $\Delta^{\prime \prime}$ can be reduced to a minimum. Here, the temporal, very heterogeneous reference measurements of terrestrial values are first passed through a special routine (Schindler 2014). For each time series containing measured values in a specified range around the reference measurement of the PSI process, where the reference measurements do not already match, transformation values can be calculated automatically. Otherwise, if the time points of the reference measurements vary more than allowed, an individual transformation is required. The transformation and the error analysis are implemented through various VBA (Visual Basic for Applications) based Microsoft Excel modules (Schindler 2014).

\section{Basis and conception of the error analysis}

The identification of adjacent TER and PS on spatial and temporal corridors allows the comparison of many unique pairings $C_{i j}$ of these (Schindler 2014). Within the $C_{i j}$ pairs, repetitions of PS points are possible, since for each TER value in the spatial corridor there can be many adjacent PSI points. The domain of the spatial corridor corresponds to a cube with a maximum edge length $\Delta L_{\text {lim }}$ (Fig. 7).

\section{Spatial corridors}

As illustrated in Fig. 7, a prerequisite for the automated definition of pairings is the geo-referencing of all points in a uniform geodetic coordinate system (Gauß-Krüger). The deviation in the geo-referencing for this project can be up to $\pm \sqrt{2} \mathrm{~m}$. Using Eq. 2, a common reference point $\left(\mathrm{x}_{0}, \mathrm{y}_{0}\right)$ is first transformed to a positional vector for the terrestrial measurement $\overrightarrow{l_{T E R, j}}$ and the PS measurement $\overrightarrow{l_{P S, l}}$. In the next step, the vector $\overrightarrow{L L}_{l j}$ is calculated by the difference between the positional vectors (Eq. 3). In the last step, each potential pair is checked component-wise to see if the corresponding vector $\Delta \vec{L}_{l j}$ exceeds the allowable value $0.5 \Delta L_{\text {lim }}$ of the spatial corridor. If so, the pairing $\mathrm{C}_{\mathrm{ij}}$ in the spatial corridor can be confirmed.

$$
\begin{aligned}
& \overrightarrow{l_{P S, i}}=\left(\begin{array}{c}
x_{P S, i} \\
y_{P S, i}
\end{array}\right) \quad \overrightarrow{l_{T E R, j}}=\left(\begin{array}{c}
x_{T E R, j} \\
y_{T E R, j}
\end{array}\right) \\
& |\Delta \vec{L} i j|=\left|\overrightarrow{l_{T E R, j}}-\overrightarrow{l_{P S, i}}\right| \\
& =\left(\begin{array}{c}
\left|x_{T E R, j}-x_{P S, i}\right| \\
\left|y_{T E R, j}-y_{P S, i}\right|
\end{array} \mid\right) \leq\left|\Delta L_{\text {lim }} / 2\right| \\
& =\left(\begin{array}{c}
\frac{\Delta L_{\text {lim }}}{2} \\
\frac{\Delta L_{\text {lim }}}{2}
\end{array}\right)
\end{aligned}
$$

\section{Temporal corridors}

The introduction of temporal corridors allows different measurement time points to be considered. A large temporal corridor can significantly enhance the size of the sample pairs $C_{\mathrm{ij}}$, however at the expense of an 


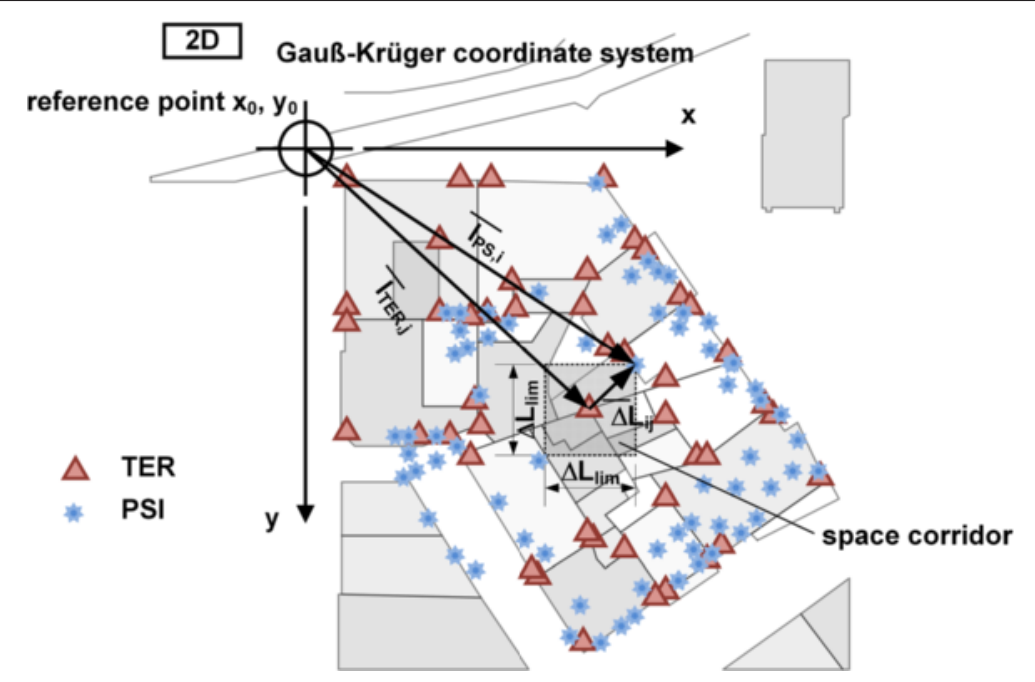

Fig. 7 Definition of neighbouring terrestrial (TER) and Persistent Scatterer (PS) settlement data points, acc. to (Schindler 2014)

increasing deviation $\Delta_{\mathrm{PS}, \mathrm{ij}}$. This increase is not due to measurement errors, but rather to the fact that with increasing temporal or spatial distances, real settlement differences can occur. This is important especially in the immediate vicinity of the TBM, because it must be assumed that major shifts can occur within a few days of operation. To minimize the impact of this effect, the time corridor is set to a maximum of 5 days. Basically, the largest time corridor must always be less than half the repetition rate (11 days) of the TerraSAR-X satellite. Otherwise, the satellite- based measurements of $\mathrm{C}_{\mathrm{ij}}$ pairings can no longer be attributed to a unique value or duplications are introduced which artificially enlarge the sample size. The effects of temporal corridors are explained in more detail in section 5.2.

In the error analysis, the deviations $\Delta_{\mathrm{PS}, \mathrm{ij}}$ are calculated for:

a.) pairs $C_{i j}$ that have already been identified in a spatial corridor and

b.) are within a pre-defined temporal corridor.

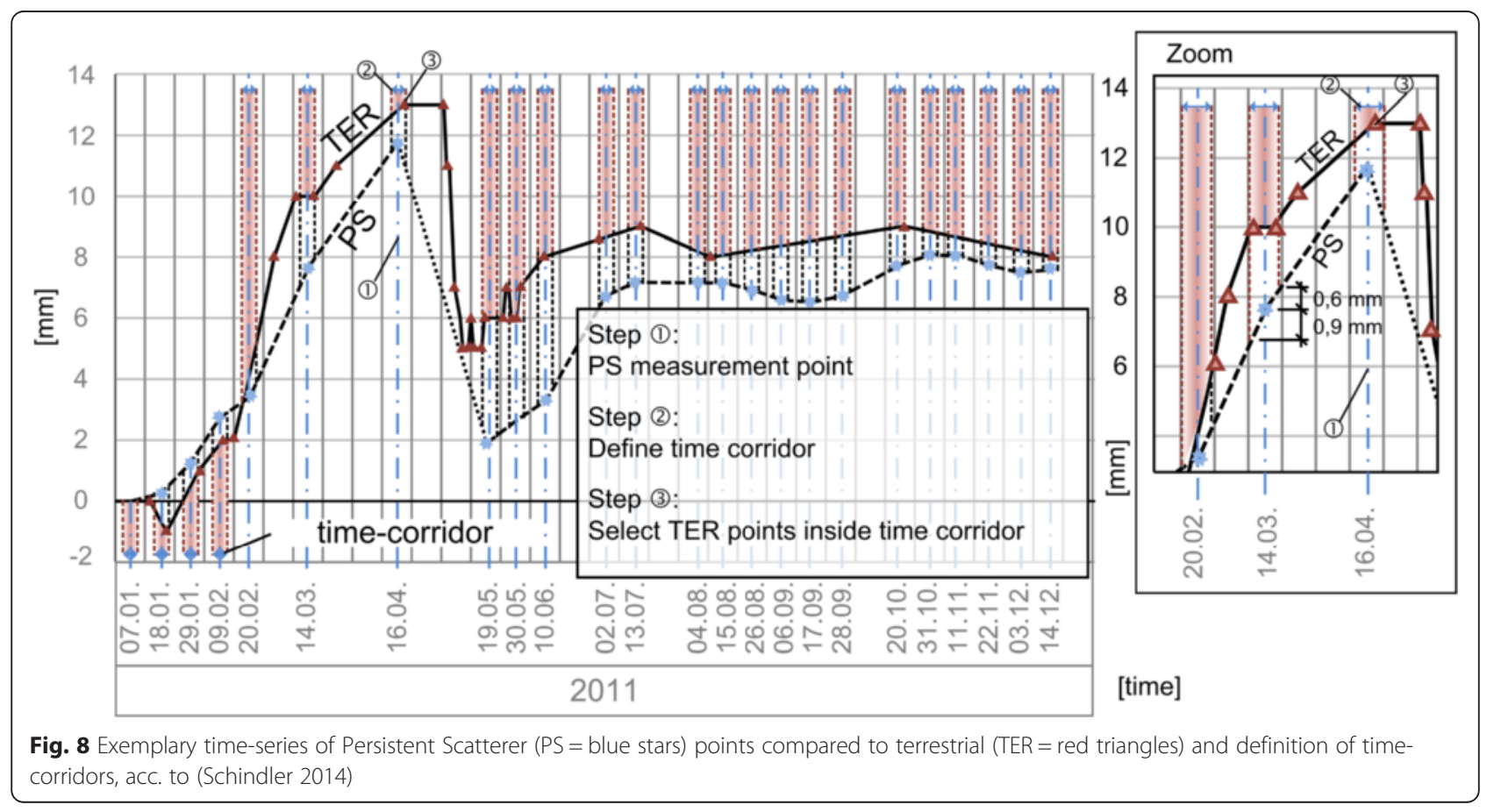



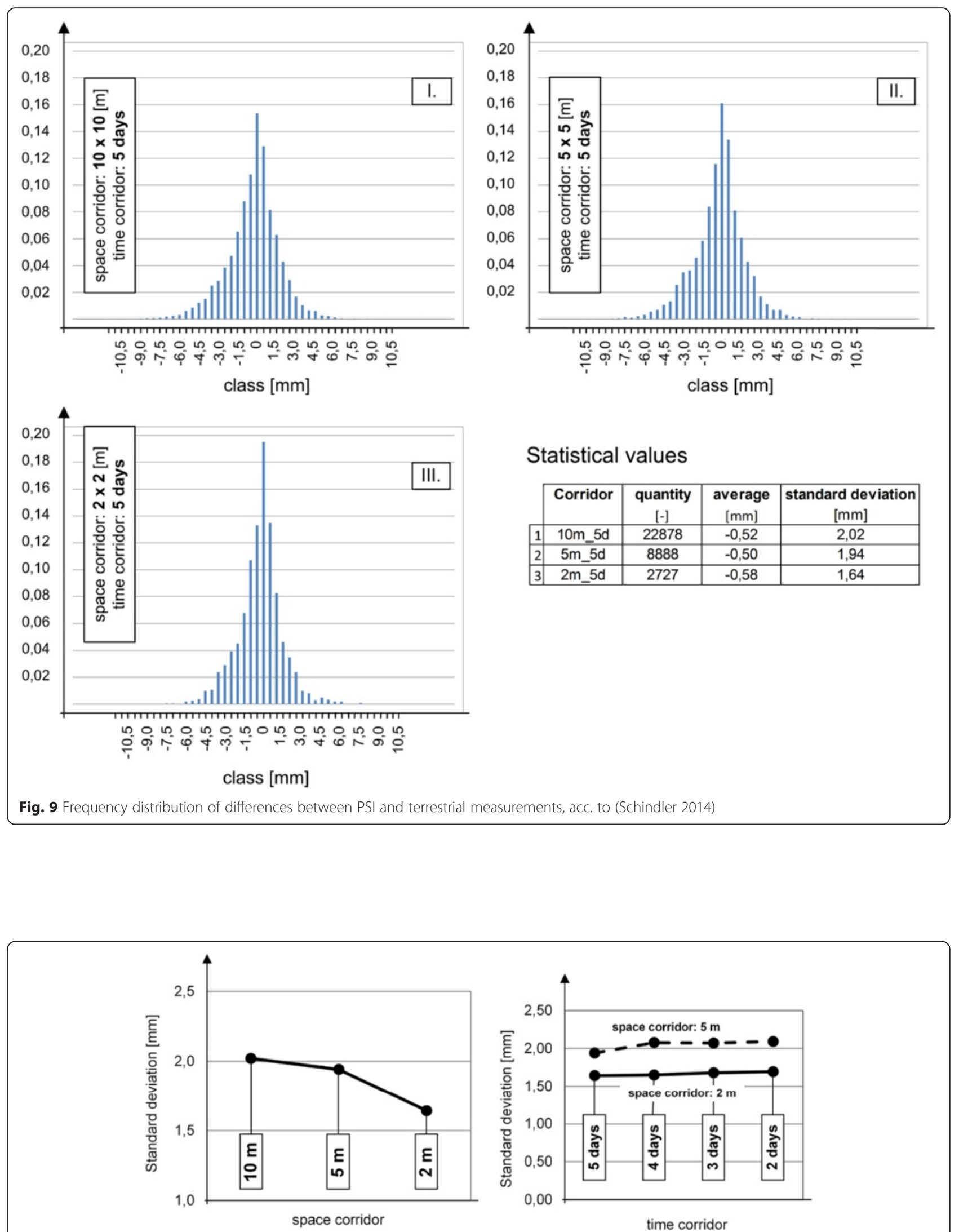

Fig. 10 Influence of space and time corridor on standard deviations, acc. to (Schindler 2014) 
Figure 8 illustrates for an exemplary pairing $C_{i j}$ consisting of a PS time series and the associated TER time series, the steps executed for the identification of the measured values in the time corridor. The grey shaded areas indicate the temporal corridors in each case, starting from the time points of the PS defined values (Step 1+2). In Step 3, each time corridor is checked to see if some TER values are within the corridor. Finally, the pairings $C_{i j}$ can be identified (see also the zoom section in Fig. 8).

With increasing differences of the gradient slopes of TER and PS settlement curves, the corresponding deviation $\Delta_{\mathrm{PS}, \mathrm{ij}}$ also increases rapidly. Thus, the error pertaining to the temporal corridor at 14.03.2011 in Fig. 8 (zoom), for example, is about $0.6 \mathrm{~mm}$ and $0.9 \mathrm{~mm}$ (no TER settlement slope, PS settlement slope very steep).

\section{Results and discussion}

To estimate the accuracy of the radar interferometric settlement monitoring at the Wehrhahn-Linie in Düsseldorf, the deviations $\Delta_{\mathrm{PS} \text {,ij }}$ are first calculated for various combinations of spatial and temporal corridors. The number of identified pairs $\mathrm{C}_{\mathrm{ij}}$ along a one kilometre of the tunnelling axis varies between ca. 23,000 (10 m and 5 days) and 1,900 ( $2 \mathrm{~m}$ and 2 days). Altogether, approximately 400,000 readings, both terrestrial and satellitebased, were recorded throughout the shield drive from January to December 2011. In the next step, all combinations of possible statistical parameters were evaluated, whereby the influence of sample sizes was also taken into account. Figure 9 shows how the number of the values for each selected combination of spatial and temporal corridors varies. In addition to the evaluation of the frequency distribution, the standard deviation is also a suitable tool to measure data accuracy (Niemeier 2008). The normalized frequency distributions of the deviations $\Delta_{\mathrm{PS}, \mathrm{ij}}$ in Fig. 9 show a cluster around $0 \mathrm{~mm}$ for the spatial corridors $10 \mathrm{~m}, 5 \mathrm{~m}$ and $2 \mathrm{~m}$ with a time corridor of 5 days. Although this accumulation appears to be bell shaped, a normal distribution could not be detected by the chi-square test. The extension of the bell shaped distribution is correlated to the error influence of increasing distances between measuring points. For example, a spatial corridor of $10 \mathrm{~m}$ contains about $62 \%$ of the variations within an interval of $\Delta_{\mathrm{PS}, \mathrm{ij}}= \pm 1.5 \mathrm{~mm}$. With a reduction of the corridor to $2 \mathrm{~m}$, the proportion rises to over $70 \%$. The development of the standard deviation in Fig. 9 confirms the increasing influence of the distance between measuring points for deviations $\Delta_{\mathrm{PS}, \mathrm{ij}}$. Due to the fact that the largest settlements in the study area are limited to about $10 \mathrm{~mm} /$ year, the curve of the standard deviation approaches a limit asymptotically with increasing size of the geographic corridor. Therefore, an evaluation of even larger corridors was omitted.
On the other hand, a reduction of the corridor to less than two meters leads to a steady decrease of the deviations $\Delta_{\mathrm{PS}, \mathrm{ij}}$ and the associated standard deviation. Due to the maximum possible geo-referencing error of $\pm \sqrt{2} \mathrm{~m}$, the smallest examined spatial corridor was set to $2 \mathrm{~m}$ in this error analysis.

While the size of the spatial corridor influences the degree of errors as expected, the influence of the time corridor is difficult to interpret. In Fig. 10 (left), the standard deviation for the three tested spatial corridors of $10 \mathrm{~m}, 5 \mathrm{~m}$ and $2 \mathrm{~m}$ is shown for each of the spatial corridors of 5 days. Figure 10 (right) shows, however, the small influence of the temporal corridors of 2, 3, 4 and 5 days, which seems to be independent of the spatial corridors. However, this behaviour cannot be generalized, since a visual analysis of the deviations (see section 5.3) shows that pairings are underrepresented where settling occurs at high rates (for example, directly under the TBM). It can be assumed, however, that for tunnelling operations a reduction of the time corridor will also decrease the standard deviation, as the tunnelling advancement and, therefore, the induced settlements are considered to be continuous.

Figures 11 and 12 present the evaluation of the accuracy of all measurements using the method of radar interferometry pairings (PS and DS points). In implementing the settlement monitoring, in addition to the tried and tested Persistent Scatterer Interferometry (PSInSAR ${ }^{\mathrm{TM}}$ ) method, available since 2001, a newer evaluation method was used (Ferretti et al. 2011). Through the evaluation of Distributed Scatterer (DS), the density of measurements has been increased. In this project, an inner-city area with little vegetation, the relation of the number of DS points to PS points was about $20 \%$. The separate analysis of PS and DS points in Fig. 11, however, shows an average of 1 millimetre higher standard deviation of the DS points compared to the PS points.

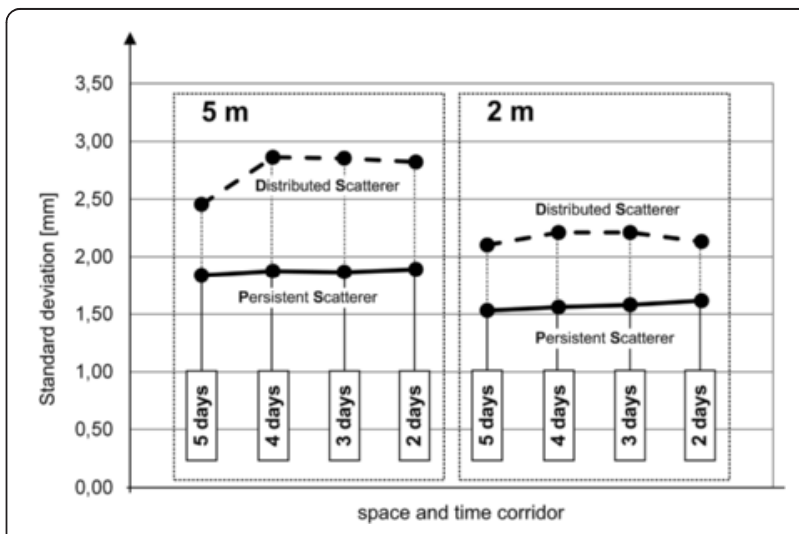

Fig. 11 Accuracy comparison of Distributed Scatterer (DS) and Persistent Scatterer (PS), acc. to (Schindler 2014) 


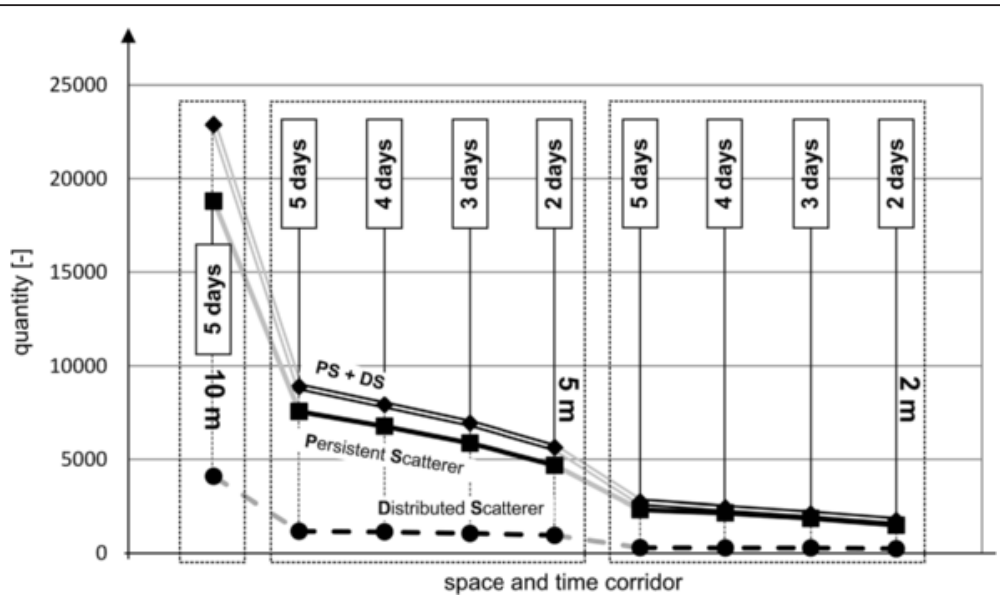

Fig. 12 Comparison of quantity (number of data points) as functions of space and time corridors, acc. to (Schindler 2014)

The number of comparative figures is shown in Fig. 12, distinguished by the evaluation method (Persistent Scatterer or Distributed Scatterer), and the specified spatial and temporal corridors. For the spatial corridor of $10 \mathrm{~m}$, the evaluations were performed with just a time interval of 5 days. Under the conditions of the present project, the accuracy of the Distributed Scatterer is about half as good as the Persistent Scatterer.

The evaluation of other statistical values (Table 1), such as the mean values of the individual radar images in Fig. 13 (top), confirms further influences on the accuracy of a radar interferometric settlement monitoring. The development of the statistical average of the deviations $\Delta_{\mathrm{PS}, \mathrm{ij}}$ is correlated with temperature or atmospheric changes during the summer months. This agrees well with the results of Schäfer (Schäfer 2012), who could detect a greater influence of the phase component of the atmosphere $\left(\phi_{\text {path }}\right)$ during the summertime. A subsequent correction and improvement of the Persistent Scatterer based on weather records is thus theoretically possible. The steady increase of the standard deviations for a constant number of pairings $C_{i j}$ (Fig. 13, centre) represents a systematic error in the processing chain of radar images. Therefore, a correction of this error component is recommended for time series of more than 1 year.

\section{Visual analysis of deviations in 3D space}

In addition to using statistical analyses to estimate the accuracy of measurement data, providing a visual analysis of data sources within a VR environment can be very helpful. As described previously, the accuracy of terrestrial and satellite-based measurements, as well as the deviations $\Delta_{\mathrm{PS}, \mathrm{ij}}$, can be visualised in different time steps. Sources of error that affect the degree of accuracy, such as atmospheric conditions, systematic errors in the evaluation of radar images and local
Table 1 Assembly of statistical values in different space and time corridors

\begin{tabular}{|c|c|c|c|c|c|}
\hline & & Quantity & Average & Variance & StAND. DEV \\
\hline & & {$[-]$} & {$[\mathrm{mm}]$} & {$[\mathrm{mm}]$} & {$[\mathrm{mm}]$} \\
\hline \multirow[t]{3}{*}{ 10m_5d } & overall & 22878 & $-0,52$ & 4,09 & 2,02 \\
\hline & PS & 18796 & $-0,39$ & 3,24 & 1,80 \\
\hline & DS & 4082 & $-1,15$ & 7,53 & 2,74 \\
\hline \multirow[t]{3}{*}{$5 \mathrm{~m} \_5 d$} & overall & 8888 & $-0,50$ & 3,77 & 1,94 \\
\hline & PS & 7560 & $-0,42$ & 3,38 & 1,84 \\
\hline & DS & 1176 & $-0,84$ & 6,02 & 2,45 \\
\hline \multirow[t]{3}{*}{$5 m \_4 d$} & overall & 7909 & $-0,66$ & 4,33 & 2,08 \\
\hline & PS & 6771 & $-0,51$ & 3,51 & 1,88 \\
\hline & DS & 1138 & $-1,57$ & 8,20 & 2,86 \\
\hline \multirow[t]{3}{*}{$5 \mathrm{~m} \_3 d$} & overall & 6927 & $-0,64$ & 4,30 & 2,07 \\
\hline & PS & 5869 & $-0,50$ & 3,48 & 1,87 \\
\hline & DS & 1058 & $-1,42$ & 8,15 & 2,85 \\
\hline \multirow[t]{3}{*}{$5 \mathrm{~m} \_2 d$} & overall & 5629 & $-0,66$ & 4,39 & 2,10 \\
\hline & PS & 4675 & $-0,54$ & 3,57 & 1,89 \\
\hline & DS & 954 & $-1,26$ & 7,96 & 2,82 \\
\hline \multirow[t]{3}{*}{ 2m_5d } & overall & 2727 & $-0,58$ & 2,70 & 1,64 \\
\hline & PS & 2327 & $-0,56$ & 2,34 & 1,53 \\
\hline & DS & 296 & $-1,03$ & 4,42 & 2,10 \\
\hline \multirow[t]{3}{*}{$2 m \_4 d$} & overall & 2488 & 0,45 & 2,76 & 1,65 \\
\hline & PS & 2150 & $-0,53$ & 2,44 & 1,56 \\
\hline & DS & 281 & $-0,86$ & 4,89 & 2,21 \\
\hline \multirow[t]{3}{*}{ 2m_3d } & overall & 2182 & 0,48 & 2,83 & 1,68 \\
\hline & PS & 1861 & $-0,51$ & 2,50 & 1,58 \\
\hline & DS & 281 & $-0,86$ & 4,89 & 2,21 \\
\hline \multirow[t]{3}{*}{$2 m \_2 d$} & overall & 1829 & 0,52 & 2,88 & 1,70 \\
\hline & PS & 1499 & $-0,47$ & 2,61 & 1,62 \\
\hline & DS & 238 & $-0,62$ & 4,54 & 2,13 \\
\hline
\end{tabular}



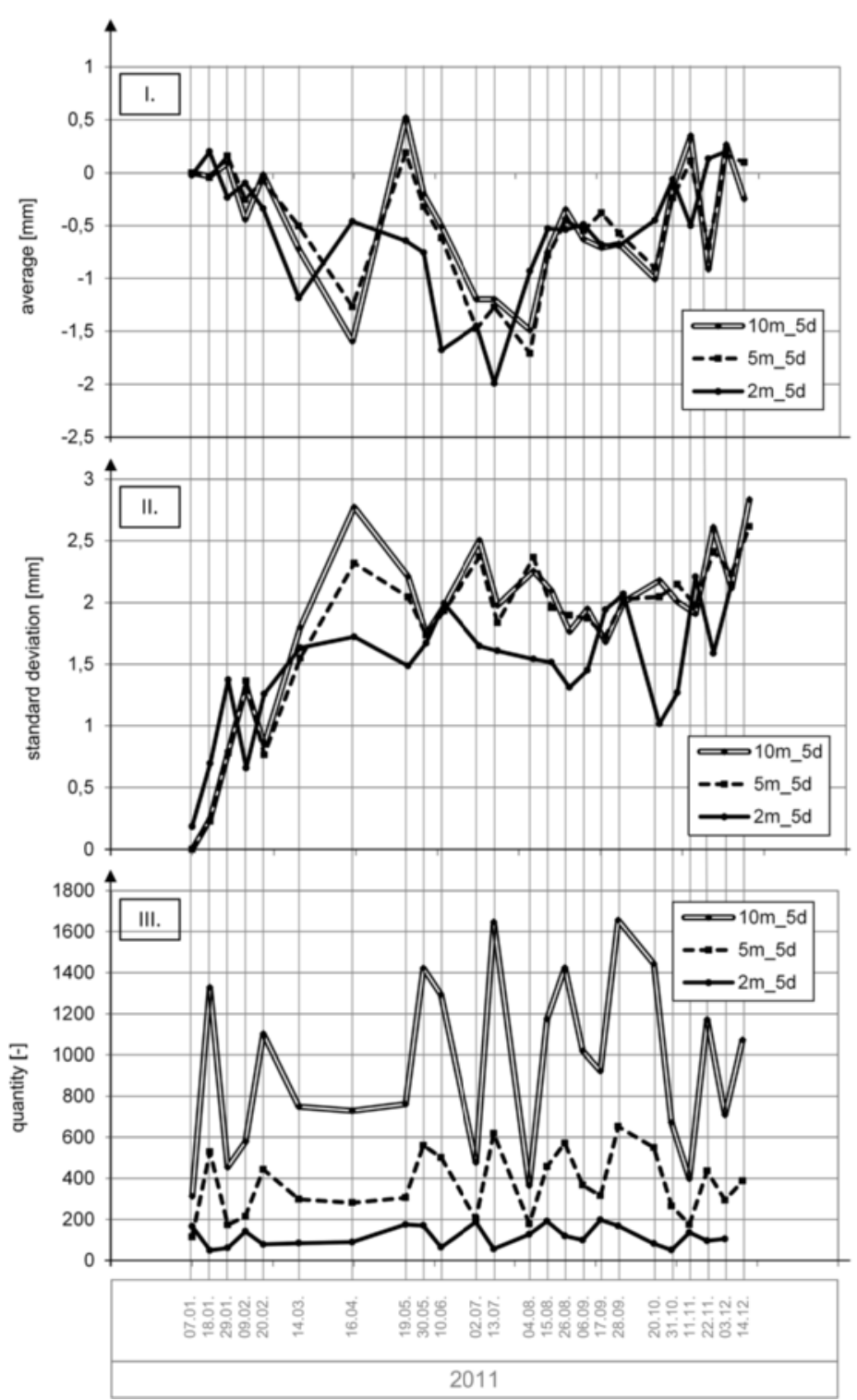

[time]

Fig. 13 Statistical values (average (I), standard deviation (II) and quantity (number of data points) (III) of all displacement values) for each radar image over time, acc. to (Schindler 2014)

events in the spatial corridor, can be quantified. The approach is exemplified on a section of the tunnel studied in this paper, where the pairings $C_{i j}$ are generally uniformly distributed, but have a somewhat greater density near built-up areas. Under green-field conditions, only a few values are to be found due to de-correlation effects.

Figure 14 shows the values of the settlements, based on terrestrial and the satellite monitoring, at the time of shield passage compared to the corresponding deviations $\Delta_{\mathrm{PS}, \mathrm{ij}}$ of the identified pairs. Although the visual analysis shows no or only small deviations, a local accumulation of significant deviations between TER and PS measurements can be recognized. If the structural situation of the site, including the geo-referencing of the settlement points, is taken into account in the VR laboratory, it can be seen that the reason for the noted deviations is caused by the choice of the spatial corridor: The construction of the building with a recessed ground floor and upper floors supported on columns leads, on the one hand, to measurements on the house construction itself (TER) and, on the other hand, to measurements of the sidewalk in front of the house (PS). The local increase of deviations $\Delta_{\mathrm{PS}, \mathrm{ij}}$ is therefore due to different settlement behaviour, caused by the structural independence of buildings and sidewalks. Although other interpretations, such as atmospheric or temperature-related disturbances, cannot be 


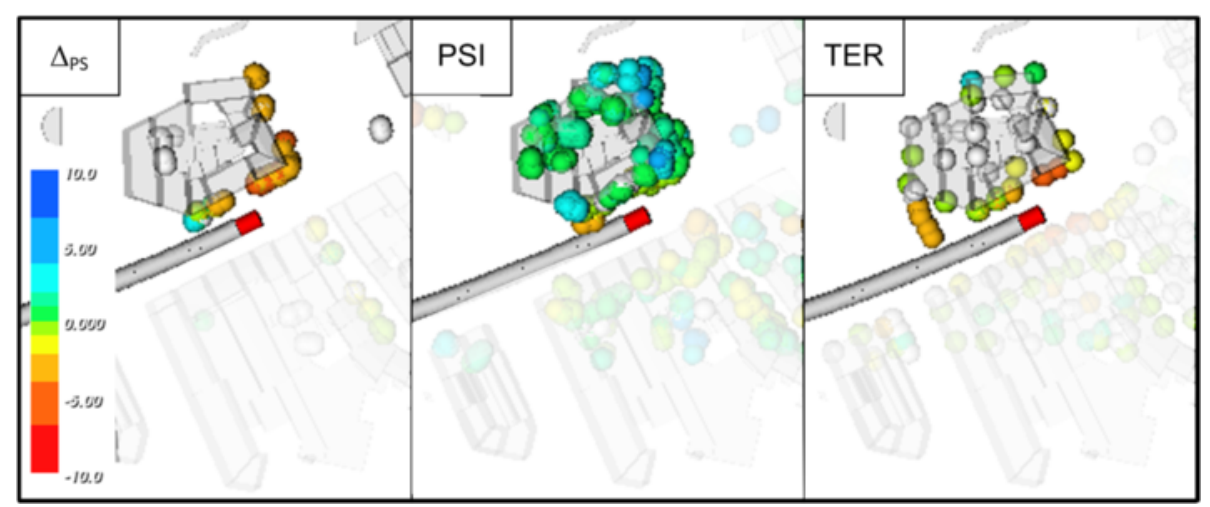

Fig. 14 Example of a visual accuracy analysis depicting the color-coded difference between satellite (PSI) and terrestrial (TER) measurement, acc. to (Schindler 2014)

excluded, they must be considered unlikely due to the local limitation of the phenomenon.

This result makes it clear that expert knowledge and further additional information (taken for example from Google Street View) are needed in the methods using remote sensing to avoid possible misinterpretations.

\section{Conclusions}

Due to the ongoing expansion of urban areas, solutions must be found to face the challenge of increasing mobility in an efficient and environment-friendly manner. One option is the extension of underground transportation systems using tunnels. However, during the construction of tunnel facilities using Tunnel Boring Machines (TBM), the risk of damage caused to buildings and other structures rises due to inevitable surface settlements. Research objectives are therefore, on the one hand, to minimize the resulting settlements by improving machine technology and, on the other hand, to control the magnitude of the settlements and their consequences by an area-wide, exact monitoring. Regarding the latter, facing the limitations of terrestrial measurement methods technological progress in satellite based remote sensing using radar waves has made it possible to capture subtle displacements on the earth's surface with millimetre accuracy (Bamler et al. 2008; Arangio et al. 2012; Giannico \& Ferretti 2012; Herrmann 2009). However, there is still a lack of scientific analyses of the accuracy of satellite based settlement monitoring resulting in low acceptance of this technology in the daily application, for example in tunnelling.

The contribution of this paper is twofold. First, this paper presents an accuracy analysis of remote satellite based settlement data in comparison with well-known terrestrial measurements within the frame of a mechanised tunnelling project. The evaluations presented in this paper demonstrate an accuracy of about $\pm 1.5 \mathrm{~mm}$ in the measurement of building and ground deformation using the method of radar interferometry in urban areas. It is concluded that the high resolution of radar images of the TerraSAR-X satellite, in combination with conventional ground-based measurements, provides a very practical, economical and effective approach to tunnelling-induced settlement monitoring.

The second contribution of this paper is a novel concept for visualising settlement data that incorporates (1) data correlating aspects within a tunnelling projects, e.g. visualising settlements within the context of buildings and the position of the boring machine, (2) different representations of discrete data points, e.g. point-oriented and area-oriented methods, (3) timedependent settlement representation in correlation with operational boring machine data, e.g. 4D animation of correlated settlement values and thrust forces of the machine, (4) standard data formats, such as the Industry Foundation Classes (IFC), and (5) a 3D virtual reality environment implementation.

Through the visualisation of settlements in accordance with the advancement of the TBM, a 3D tunnel product model can clearly show users possible interactions and influences, which would otherwise be difficult to detect. As presented in this paper, using a combination of visualisation and accuracy analysis, sources of error can be localized and interpreted, and the application of differential radar interferometry for settlement monitoring can be substantially improved.

\section{Competing interests}

The authors declare that they have no competing interests.

\section{Authors' contributions}

All authors contributed extensively to the work presented in this paper. Schindler and Hegemann reviewed and analysed the literature, conducted the accuracy analysis (Schindler), developed and implemented the visualisation concept (Hegemann), conducted the case study, analysed the results, and drafted the manuscript. Koch coordinated the research activities, contributed to the visualisation concept and co-edited the manuscript. Koenig und Mark supervised the entire research process of this study. All authors read and approved the final manuscript. 


\section{Acknowledgements}

Financial support is provided by the German Research Foundation (DFG) in the framework of the project D1 and D3 of the Collaborative Research Centre SFB 837. The SAR images of the TerraSAR-X satellite (CAL1140) are kindly provided by the German Aerospace Centre (DLR). These supports are gratefully acknowledged.

In addition, the authors would like to express their gratitude to the state capital of Düsseldorf for endorsing the research work and providing the fundamental project data.

\section{Author details}

${ }^{1}$ HOCHTIEF Engineering GmbH, Consult IKS Energy, Lyoner Straße 25, 60528 Frankfurt am Main, Germany. ${ }^{2}$ Chair of Computing in Engineering, Faculty of Civil and Environmental Engineering, Ruhr-Universität Bochum, Universitätstraße 150, 44801 Bochum, Germany. ${ }^{3}$ Centre for Structural Engineering and Informatics, University of Nottingham, University Park, Nottingham, NG7 2RD, United Kingdom. ${ }^{4}$ Institute of Concrete Structures, Faculty of Civil and Environmental Engineering, Ruhr-Universität Bochum, Universitätstraße 150, 44801 Bochum, Germany.

\section{Received: 13 November 2015 Accepted: 11 February 2016}

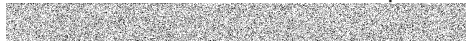

\section{References}

Arangio S., Di Mauro M., Marsella M., Sonnessa A., Manunta M.: Assessment of structural damage due to ground settlements by using the DInSAR technique. Life-Cycle and Sustainability of Civil Infrastructure Systems (IALCCE 2012), pp. 1897-1904, 2012

Bamler R., Hinz S., Eineder M.: SAR-Interferometrie für geodätische Anwendungen. Allgemeine Vermessungsnachrichten (AVN), pp. 243-252, 2008

BuildingSMART. (2015). Summary of IFC releases. http://www.buildingsmart-tech. org/specifications/ifcreleases/summary, 2015

Burland, J. B., Standing, J. R., \& Jardine, F. M. (2001). Building response to tunnelling - Case studies from construction of the Jubilee Line Extension, Volume 1: Projects and Methods. London: T. Telford.

Ferretti, A., Prati, C., \& Rocca, F. (2011). Permanent Scatterers in SAR Interferometry. IEEE Transactions on Geoscience and Remote Sensing, 39(1), 8-20.

Ferretti, A., et al. (2011). A New Algorithm for Processing Interferometric Data-Stacks: SqueeSAR. IEEE Transactions on Geoscience and Remote Sensing, 49(9), 3460-3470.

Gamma Remote Sensing: Interferometric SAR Processing, 2007, (Gamma software documentation, version 1.0), Gümlingen, Switzerland.

Gernhardt S., Adam N., Hinz S., Bamler R. (2009). Appearance of Persistent Scatterers for Different TerraSAR-X Acquisition Modes. In: Proceedings of ISPRS 2009, (pp. 1-5). Hannover, Germany.

Giannico C., Ferretti A.: Application of satellite radar interferometry for structural damage assessment and monitoring. Life-Cycle and Sustainability of Civil Infrastructure Systems (IALCCE 2012), pp. 2094-2101, 2012

Giardina, G. (2013). Modelling of Settlement induced Building Damage. Delft: Dissertation TU

Giardina, G., Floria, V., Hendriks, M., \& Rots, J. G. (2012). Vulnerability assessment of buildings subject to tunnel-induced settlements: the influence of orientation and position of the building. Bangkok: Proc. World Tunnelling Congress 2012.

Hanssen RF. U. a.: Validation of PSI Results of Alkmaar and Amsterdam within the 953 TERRAFIRMA Validation Project. Fifth International Workshop on ERS / Envisat 954 SAR Interferometry (FRINGE07), 2007

Hanssen RF:: Radar Interferometry: Data Interpretation and Error Analysis. Frascati, Italy: Kluwer Academic Press, 2001

Herrmann K.: Beweissicherung aus dem Weltall - Vermessungstechnische Sonderaufgaben beim Bau des Katzenbergtunnels. EI-EISENBAHNINGENIEUR, pp. 52-55, 2009

ITA Commitee on Underground Space (ITACUS): http://www.tta-aites.org/en/wgcommittees/committees/itacus, 2010

Jakobs, M., Dekker, H., \& Otterbein, R. (2001). Erfahrungen beim Einsatz der Druckschlauchwaage zur Höhenüberwachung setzungsempfindlicher Gebäude. Bauingenieur, 76, 283-286.

Kavvadas, M. J. (2005). Monitoring ground deformation in tunnelling: Current practice in transportation tunnels. Engineering Geology, 79(1-2), 93-113.

Klausing, H., \& Holpp, W. (2000). Radar mit realer und synthetischer Apertur. Wien Oldenburg: Verlag München.

Kymmell W.: Building information modeling: Planning and managing construction projects with 4D CAD and simulations, 2008
Mark, P., Niemeier, W., Schindler, S., et al. (2012). Radarinterferometrie zum Setzungsmonitoring im Tunnelbau - Anwendung am Beispiel der WehrhahnLinie in Düsseldorf. Bautechnik, 89(11), 764-776.

Niemeier, W. (2008). Ausgleichrechnung - Statistische Auswertemethode (2nd ed.). Berlin: de Gruyter.

Schäfer, M. (2012). Atmosphäre als Phasenbestandteil der differentiellen Radarinterferometrie und ihr Einfluss auf die Messung von Höhenänderungen. TU Clausthal: Dissertation.

Schindler, S. (2014). Monitoringbasierte strukturmechanische Schadensanalyse von Bauwerken beim Tunnelbau. Ruhr University Bochum: Dissertation.

Schindler S., Hegemann F., et al.: An interaction platform for mechanized tunelling - Application on the Wehrhahn-Linie in Düsseldorf (Germany). Geomechanics and Tunnelling, Vol. 7, Issue 1, 2014

Sherman WR, Craig AB. (2002) Understanding virtual reality: Interface, application and design. San Francisco: Morgan Kaufmann Publishers Inc.

Spence, R. (2001). Information visualization. Harlow.

Tarayre, H., \& Massonnet, D. (1996). Atmospheric propagation heterogeneities revealed by ERS-1. Geophysical Research Letters, 23, 989-992.

Van der Poel, J. T., Kaalberg, F. J., \& Gastine, E. (2005). Monitoring for construction of the North/South metro line in Amsterdam, The Netherlands. Geotechnical Aspects of Underground Construction in Soft Ground (pp. 745-749). Amsterdam: Proceedings of the 5th International Symposium TC28.

Walter, D. (2011). Systematische Einflüsse digitaler Höhenmodelle auf die Qualität radarinterferometrischer Bodenbewegungsmessungen. TU Clausthal: Dissertation.

Walter D., Wegmüller U., Spreckels V., Hannemann W., Busch W.: Interferometric monitoring of an active underground mining field with high-resolution SAR sensors. Proceedings of ISPRS Workshop, 2009

Witte, B., \& Schmidt, H. (2000). Vermessungskunde und Grundlagen der Statistik für das Bauwesen. Stuttgart: Verlag Konrad Wittwer.

\section{Submit your manuscript to a SpringerOpen ${ }^{\mathcal{O}}$ journal and benefit from:}

- Convenient online submission

Rigorous peer review

- Immediate publication on acceptance

- Open access: articles freely available online

- High visibility within the field

- Retaining the copyright to your article

Submit your next manuscript at $\boldsymbol{s p r i n g e r o p e n . c o m ~}$ 